\title{
An investigation of the relation between catalase C262T gene polymorphism and catalase enzyme activity in leukemia patients
}

Nazan Eras ${ }^{1}$, Gozde Türkoz², Anil Tombak³ ${ }^{3}$ Naci Tiftik ${ }^{3}$, Serap Yalin", Mehmet Berkoz ${ }^{5}$, Sema Erden ${ }^{6}$, Etem Akbas $^{2}$

\begin{abstract}
${ }^{1}$ Department of Medical Genetics, Faculty of Medicine, Mersin University, Mersin, Turkey 2Department of Medical Biology, Faculty of Medicine, Mersin University, Mersin, Turkey ${ }^{3}$ Department of Hematology, Faculty of Medicine, Mersin University, Mersin, Turkey ${ }^{4}$ Department of Biochemistry, Faculty of Pharmacy, Mersin University, Mersin, Turkey ${ }^{5}$ Department of Pharmaceutical Technology, Faculty of Pharmacy, Yuzuncu Yil University, Van, Turkey

${ }^{6}$ Vocational School of Health Service, Mersin University, Mersin, Turkey
\end{abstract}

Submitted: 15 January 2018; Accepted: 23 June 2018

Online publication: 12 November 2019

Arch Med Sci 2021; 17 (4): 928-933

DOI: https://doi.org/10.5114/aoms.2019.89692

Copyright (c 2019 Termedia \& Banach

\section{Abstract}

Introduction: Catalase (CAT), an antioxidant enzyme, catalyzes conversion of hydrogen peroxide to water and molecular oxygen, protecting cells against oxidative stress. The aim of this study was to investigate the possible association between CAT C262T polymorphism in the promoter region of the CAT gene and leukemia risk and to determine the relationship between CAT genotypes and CAT enzyme activities.

Material and methods: Genotypes of 102 cases and 112 healthy controls' genotypes were determined by polymerase chain reaction-restriction fragment length polymorphism methods. Catalase activity was measured with the method of Aebi.

Results: The frequencies of the T allele among the cases and controls were $28.4 \%$ and $25.9 \%$, respectively $(p=0.75)$. The frequencies of CC, CT, and TT among cases were $57.8 \%, 27.4 \%$, and $14.7 \%$, respectively, while in controls, the frequencies of CC, CT, and TT were $54.4 \%, 39.3 \%$, and $6.3 \%$, respectively, which were not significantly different. Although CAT enzyme activity was lower in leukemia patients with TT genotypes than in controls, this did not reach statistical significance $(p=0.37)$.

Conclusions: This is the first report showing that CAT C262T polymorphism is not a genetic predisposing factor for the risk of leukemia in the Turkish population. However, additional research is needed to confirm these findings.

Key words: antioxidant, catalase, leukemia, oxidative stress, polymorphism.

\section{Introduction}

Oxygen is necessary for the survival of all aerobic organisms, and while it is greatly reduced to water, a small proportion of that oxygen is converted to reactive oxygen species (ROS) during aerobic metabolism [1]. Reactive oxygen species including the superoxide anion radical, the hydroxyl radical, hydrogen peroxide, and singlet oxygen are involved in many vital physiological processes. These processes include

\section{Corresponding author:}

Nazan Eras

Department of Medical

Genetics

Mersin University School

of Medicine

33343 Mersin, Turkey

Phone: +90 3243410000

Fax: +90 3243610015

E-mail: nazaneras@gmail.com 
various signal transduction pathways that modulate the growth, proliferation and differentiation of cells in low/moderate concentrations in hematopoietic stem cells [2-4]. However, high concentrations of ROS can lead to the impairment of cellular structures and functions or cell death [5] Moreover, this can also cause damage to various cellular components including DNA, proteins, and lipids [6]. Hence, ROS-induced DNA damage can result in abnormal genetic alterations in hematopoietic stem cells that can lead to the initiation and progression of leukemia [4].

In order to avoid oxidative damage, cells biosynthesize several antioxidant enzymes, including superoxide dismutase (SOD), glutathione peroxidase, catalase (CAT), butyrylcholinesterase, and thioredoxin-peroxiredoxin [7, 8]. Superoxide dismutases convert the superoxide anion radical to hydrogen peroxide and molecular oxygen [9] The hydrogen peroxide-scavenging enzymes such as glutathione peroxidase and CAT convert hydrogen peroxide to water and oxygen [10].

Catalase (EC 1.11.1.6), the most abundant protein in erythrocytes, liver, and the kidney, generally located within peroxisomes, is a tetrameric enzyme weighing $240 \mathrm{kDa}$ that contains four porphyrin heme (iron) groups [11-13]. This enzyme is encoded by the CAT gene located in the $11 \mathrm{p} 13$ region, spanning $34 \mathrm{~kb}$, and it is composed of 13 exons and 12 introns [14]. Several single nucleotide polymorphisms (SNPs) were identified in the 5'-untranslated region of the CAT gene such as A21T (rs794316), C844T (rs769214) and C262T (rs1001179) [15].

The common polymorphism in the promoter region of the CAT gene (CAT C262T, rs1001179) consists of a $C$ to $T$ substitution at position -262 in the 5' untranslated region [16]. It has been shown that this polymorphic variation within the promoter region affects the transcriptional factor binding. Therefore, this leads to changes in transcription and subsequent expression of the CAT gene [17] Individuals carrying the $C$ allele compared to the $T$ allele have been found to have altered CAT serum concentrations and increased CAT activity [18]. Thus, increased ROS levels may influence the response to oxidative stress, leading to increased disease risk. Recently, a series of studies has demonstrated the associations between the CAT C262T polymorphism and risk for various diseases, such as hepatocellular carcinoma [19], prostate cancer [20], invasive cervical cancer [21], endometriosis [22], ulcerative colitis [23], etc. However, no significant association was found between CAT C262T polymorphism and susceptibility to myeloid leukemia [24, 25].

Thus, further detailed studies are necessary to demonstrate the association between CAT C262T polymorphism and leukemia risk. For this reason, the purpose of our study was to investigate the possible association between CAT C262T polymorphism and its enzyme activity in leukemia.

\section{Material and methods}

\section{Patients and tissue samples}

The sample consisted of 102 patients (32 ALL (acute lymphoblastic leukemia), 32 acute myeloid leukemia (AML), 17 chronic lymphocytic leukemia (CLL) and 21 chronic myeloid leukemia (CML)) recently diagnosed and under treatment at the Department of Hematology. Healthy volunteers were randomly chosen from the general population of the same area. The general inclusion criterion for controls was no evidence of cancer or history of cancer. The general exclusion criteria for controls were: any intake of regular medication, active smoking, regular high-dose vitamin supplementation during 3 months prior to the study. These individuals participated in a previously published case-control study. The cases and controls have been described previously in terms of data collection and study procedures [26]. This study has the approval of the Ethics Committee, Faculty of Medicine, The University of Mersin. All participants were informed about the aim and design of the study.

\section{Genotype analysis}

Blood samples from all study participants were collected into the tubes containing $50 \mathrm{mmol} / \mathrm{l} \mathrm{di}$ sodium-EDTA. Genomic DNA was extracted from peripheral whole blood with the standard phenol/chloroform-based method. All extracted DNA samples were stored at $4^{\circ} \mathrm{C}$ until further analysis. All DNA samples from cases and controls were genotyped by polymerase chain reaction (PCR), followed by restriction fragment length polymorphism (RFLP) analysis. In order to avoid potential contamination, the PCR assays were performed with at least one known DNA genotype (positive control) and one negative control (without DNA template). CAT-262 C/T polymorphism was determined using an antisense primer 5'-AGAGCCTCGCCCCGCCGGACCG-3' and sense primer 5'-TAAGAGCTGAGAAAGCATAGCT-3' [27]. Polymerase chain reaction was performed in a $50 \mu$ l volume with $50 \mathrm{ng}$ of genomic DNA, $100 \mu \mathrm{m}$ dNTPs, 20 pmol of each primer, $2 \mathrm{mM} \mathrm{MgCl}, 1 \times \mathrm{PCR}$ buffer with $\left(\mathrm{NH}_{4}\right)_{2} \mathrm{SO}_{4}$ and $2 \mathrm{U}$ Taq polymerase. Amplification was carried out in a TC-512 Thermal Cycler (Techne), and the cycling conditions were: $95^{\circ} \mathrm{C}$ for $15 \mathrm{~min}, 35$ cycles of $94^{\circ} \mathrm{C}$ for $30 \mathrm{~s}, 60^{\circ} \mathrm{C}$ for $45 \mathrm{~s}$, $72^{\circ} \mathrm{C}$ for $30 \mathrm{~s}$, and a final extension at $72^{\circ} \mathrm{C}$ for $10 \mathrm{~min}$. Amplicons (185 bp) were digested with $10 \mathrm{U}$ of Smal (Promega, Southampton, UK) at $37^{\circ} \mathrm{C}$ for 


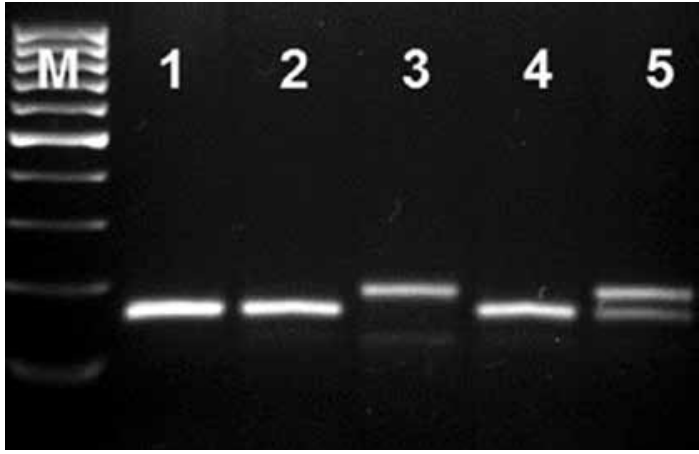

Figure 1. CAT-262 C/T genotyping by PCR-RFLP. M: 100-bp ladder; Lanes 1, 2, 4: C/C (155 bp); 3: T/T (185 bp); 5: C/T (185, 155 bp)

$16 \mathrm{~h}$ and analyzed following the electrophoresis in 3\% agarose gel stained with ethidium bromide $(0.5 \mu \mathrm{g} / \mathrm{ml})$. The $\mathrm{T}$ allele was not digested, giving a 185-bp fragment; the $C$ allele was digested, showing two fragments of 155 and $30 \mathrm{bp}$ (due to limitation of agarose gel in the detection of fragments that are smaller than $50 \mathrm{bp}$, the $30 \mathrm{bp}$ fragment was invisible) (Figure 1). Genotyping was performed blindly with respect to case/control status and repeated twice for all subjects, but no discordant genotype classifications were identified.

\section{Plasma samples}

Ten milliliters of fresh venous blood in lithium heparin were taken from each subject and immediately centrifuged at $1000 \times \mathrm{g}$ for $10 \mathrm{~min}$ at $4^{\circ} \mathrm{C}$. The supernatant plasma was aspirated, transferred to a polypropylene tube and fresh plasma samples subsequently were stored at $-80^{\circ} \mathrm{C}$ until further analysis.

\section{Analysis of catalase activity}

Catalase activity was measured by the method of Aebi [28]. This method is based on the principle that spectrophotometric recording of the initial rate of hydrogen peroxide disappearance (0-60 s) is at a wavelength of $240 \mathrm{~nm}$. Catalase enzyme activity is expressed as $\mathrm{U} / \mathrm{ml}$ of plasma.

\section{Statistical analysis}

Allele and genotype frequencies among cases and controls were calculated by logistic regression and the $\chi^{2}$ test. The deviation from Hardy-Weinberg equilibrium was examined by $\chi^{2}$. Mann-Whitney $U$ test, Kolmogorov-Smirnov, and independent $t$ tests were used to assess differences in CAT activities according to the genotypes between the patient and control groups. Results were reported as the mean \pm SD. The analysis of data was performed using SPSS software package version 11.5 for Windows. P-values less than 0.05 were accepted as statistically significant. Post hoc power analysis with pre-established effect size, error probability, and sample size was carried out using the $G^{*}$ Power version 3.1.3 program.

\section{Results}

Table I shows the demographic characteristics of the case and control groups. The mean age of the 2 groups was similar: 51.3 years in the case group and 49.3 years in the control group. Distribution of gender was similar in both groups $(p=0.81)$. We included AML, CML and CLL patients (except $\mathrm{ALL}$ ) to make a comparison among age groups, because ALL is commonly seen in young people. We observed that the patients between 41 and 50 years had 4.4 -fold $(p=0.002)$ and the patients 51 years and older had 4.8-fold ( $p=0.001)$ higher leukemia risk compared to the patients 30 years and younger.

As shown in Table II, the frequencies of $\mathrm{C}$ and $T$ alleles were $71.6 \%$ and $28.4 \%$ in the cases and $74.1 \%$ and $25.9 \%$ in the controls, respectively. These differences were not significant $(p=0.75)$. The frequencies of the CC, CT and TT genotypes in cases were $57.8 \%, 27.4 \%$ and $14.7 \%$, respectively and $54.4 \%, 39.3 \%$ and $6.3 \%$ in controls, respectively. Compared with the CC genotype, OR for the CT and TT genotypes were 0.65 (95\% Cl: 0.36-1.19) and 2.21 (95\% Cl: 0.84-5.82), respectively. In addition, the $\chi^{2}$ test was used to determine whether there was a relationship between groups and genotypes $\left(\chi^{2}=6.044, p=0.049\right)$. This relationship at borderline significance might become clearer by increasing the sample size. CAT genotype frequencies were in Hardy-Weinberg equilibrium in the control group $(p=0.802)$, but not in the patient group $(p=0.002)$. Using power calculation we demonstrated that the study had $97.5 \%$ power in detecting associations of CAT-262 C/T polymorphism with risk of leukemia, at a significance level of $0.30(\mathrm{~d} f=2)$.

We also investigated the relation between CAT genotypes and CAT enzyme activities. Catalase enzyme activity of the individuals with TT genotypes belonging to CAT C262T polymorphism was found to be $143.75 \pm 105.81 \mathrm{U} / \mathrm{ml}$ in the control group, and decreased to $101.79 \pm 70.15 \mathrm{U} / \mathrm{ml}$ in leukemic patients, but this did not reach statistical significance $(p=0.37)$. The individuals with CT genotypes had lower CAT enzyme activities in patients with leukemia $(132.81 \pm 86.86 \mathrm{U} / \mathrm{ml})$ compared to the control group $(188.63 \pm 119.41 \mathrm{U} / \mathrm{ml})(p=0.03)$ (Table III).

\section{Discussion}

Extrinsic factors such as ROS or ionizing radiation accumulate over time and can result in DNA mutations, deletions or translocations by induc- 
Table I. Characteristics of patients and controls

\begin{tabular}{|lcccc|}
\hline Factor & Patients, $n$ (\%) & Controls, $n$ (\%) & $P$-value & OR (95\%) \\
\hline \begin{tabular}{l} 
Gender: \\
\hline Male
\end{tabular} & $52(50.9)$ & $60(53.6)$ & 0.81 & $0.9(0.52-1.54)$ \\
\hline Female & $50(49.1)$ & $52(46.4)$ & - & 1.0 \\
\hline Age: & & & & \\
\hline$\leq 30$ & $8(11.6)$ & $14(12.5)$ & - & 1.0 \\
\hline $31-40$ & $7(10.1)$ & $24(21.4)$ & 0.099 & $2.28(0.85-6.07)$ \\
\hline $41-50$ & $11(15.9)$ & $41(36.6)$ & 0.002 & $4.46(1.71-11.62)$ \\
\hline$\geq 51$ & $43(62.3)$ & $33(29.5)$ & 0.001 & $4.85(2.17-10.86)$ \\
\hline Subtype: & $32(31.4)$ & - & - & - \\
\hline ALL & $32(31.4)$ & - & - & - \\
\hline AML & $17(16.6)$ & - & - & - \\
\hline CLL & $21(20.6)$ & - & - & - \\
\hline CML & AML & & & - \\
\hline
\end{tabular}

ALL - acute lymphoblastic leukemia, AML - acute myeloid leukemia, CLL - chronic lymphocytic leukemia, CML-chronic myeloid leukemia.

Table II. Genotype and allele distribution of the CAT C262T polymorphism in cases and controls

\begin{tabular}{|lcccc|}
\hline Variable & Cases, $n(\%)$ & Controls, $n(\%)$ & $P$-value & OR $(95 \% \mathrm{Cl})$ \\
\hline \begin{tabular}{l} 
Genotype frequencies: \\
\hline CC
\end{tabular} & $59(57.8)$ & $61(54.4)$ & - & 1.0 \\
\hline CT & $28(27.4)$ & $44(39.3)$ & 0.17 & $0.65(0.36-1.19)$ \\
\hline TT & $15(14.7)$ & $7(6.3)$ & 0.11 & $2.21(0.84-5.82)$ \\
\hline Allele frequencies: & & & & \\
\hline C & $73(71.6)$ & $83(74.1)$ & - & 1.0 \\
\hline T & $29(28.4)$ & $29(25.9)$ & 0.75 & $0.88(0.48-1.60)$ \\
\hline
\end{tabular}

Post hoc power analysis: $d f=2, n=224$. Effect size $n=0.30$; power $(1-\beta$ err prob) $=0.975$

Table III. Findings of CAT C262T genotypes and catalase activity $(\mathrm{U} / \mathrm{ml})$ in patients and controls

\begin{tabular}{|lccccc|}
\hline Genotype & \multicolumn{2}{c}{ Patients } & \multicolumn{2}{c}{ Controls } & \multirow{2}{*}{$P$-value } \\
\cline { 2 - 5 } & $n$ & Mean \pm SD & $n$ & Mean \pm SD & \\
\hline CC & 59 & $164.08 \pm 148.23$ & 61 & $174.98 \pm 138.57$ & 0.67 \\
\hline CT & 28 & $132.81 \pm 86.86$ & 44 & $188.63 \pm 119.41$ & 0.03 \\
\hline TT & 15 & $101.79 \pm 70.15$ & 7 & $143.75 \pm 105.81$ & 0.37 \\
\hline
\end{tabular}

ing double strand breaks in hematopoietic stem cells [29]. Under normal conditions, autophagy prevents ROS accumulation through elimination of damaged mitochondria. However, dysregulation of autophagy may lead to development of tumorigenesis through the accumulation of oncogenic mutations and malignant transformation [30]. Autophagy eliminates damaged or harmful cel- lular components, whereas catalase plays an important protective role by detoxifying ROS [31]. In this population-based case-control study, we examined the association of $C 262 T$ polymorphism in the promoter region of the CAT gene with the risk of leukemia in a Turkish population. Furthermore, we investigated the effect of genotype on CAT enzyme activity in Turkish leukemia patients. 
We analyzed the relation between leukemia and age, because advanced age is the most important risk factor for cancer overall. Within this context, increased risk was observed for advanced age in the case group excluding ALL.

In our study, the TT genotype incidence of the CAT C262T polymorphism in the control group was found to be $6 \%$ in Mersin province located in the southern part of Turkey. Suzen et al. [32] also found TT genotype frequency of the healthy individuals living in Ankara, in the central region of Turkey, as 6\%. Tefik et al. [33] reported TT genotype frequency of healthy individuals as $10.2 \%$ in Istanbul, which is slightly higher than our genotype frequencies. Moreover, the TT genotype frequency of healthy individuals was $9 \%$ and $6 \%$ in Swedish [27] and German populations [34], respectively. This distribution of genotypes is similar to that seen in our control group. However, no healthy individual with TT genotype was found in a Chinese population [35].

Some SNPs in the CAT gene lead to amino acid alterations at a specific location of the gene. One of these SNPs is CAT C262T polymorphism, which is located in the promoter region [20]. Several studies were performed in order to investigate the correlation between CAT genotype and cancer risk [20, 21, $36,37]$. A meta-analysis of 5 case-control studies including 3865 cases and 28224 controls demonstrated that C262T polymorphism was correlated with increased prostate cancer risk $(\mathrm{OR}=1.094$, 95\% Cl: 1.015-1.178, $p=0.018$ ) [20]. Another meta-analysis conducted in 2015 with 22 case-control studies involving 9777 cancer patients and 12223 controls also indicated a significant association between prostate cancer risk and C262T polymorphism (TT vs. CC: OR $=1.81,95 \% \mathrm{Cl}: 1.07-3.04$, $p=0.03$; TT vs. CT + CC: OR $=1.61,95 \%$ Cl: $1.17-$ $2.22, p=0.004)$. However, such an association was not significant for breast cancer and non-Hodgkin lymphoma (all $p>0.05$ ) [36]. Castaldo et al. [21] reported that individuals with $\mathrm{TT}$ genotype had increased risk for invasive cervical cancer $(\mathrm{OR}=3.034$, 95\% Cl: 1.462-6.298, $p=0.003)$. Quick et al. [37] found that CT or TT genotype carriers using hormone replacement therapy were at increased breast cancer risk (OR $=1.88 ; 95 \% \mathrm{Cl}: 1.29-2.75)$. In contrast, no correlation was observed between CAT C262T polymorphism and myeloid leukemias in two different studies $(p=0.17, p=0.98)[24,25]$, which is consistent with our results.

Endogenous antioxidant enzymes are designed to destroy ROS. Analysis of allelic variants of the CAT gene and measurements of CAT activities can give a more complete view of CAT status, because they reflect the underlying genetic backgrounds and environmental effects of CAT. Our data showed that the TT variant had significantly lower
CAT activity than CC and CT variants in our study group. One study reported that CAT levels were significantly higher in donors carrying the $T$ allele in comparison to donors homozygous for the $\mathrm{C}$ allele $(p<0.03)$ [27]. In contrast, another study showed that CAT TT homozygotes had significantly lower CAT activity than did CT and CC genotypes in Caucasians and African Americans [18]. This finding is consistent with our results.

In this study, we investigated whether the activity of CAT has a protective effect against the oxidative stress conditions in individuals carrying the TT polymorphic genotype. There was no relationship between CAT C262T polymorphism and CAT enzyme activity in leukemia patients. One study suggested that the -262TT genotype of the CAT gene was significantly associated with higher erythrocyte CAT activity in blood of diabetic neuropathy patients compared to the $-262 \mathrm{CC}$ genotype $\left(17.8 \pm 2.7 \times 10^{4} \mathrm{IU} / \mathrm{g} \mathrm{Hb}\right.$ vs. $13.5 \pm 3.2 \times 10^{4}$ $\mathrm{IU} / \mathrm{g} \mathrm{Hb}, p=0.0022$ ) [38]. Ho et al. [39] observed that patients with adenocarcinoma had significantly lower levels of CAT activity compared with healthy controls in those with CC genotype of the CAT gene $(p<0.05)$.

In conclusion, to the best of our knowledge, this is the first case-control study in the Turkish population which investigates the relation not only between CAT C262T polymorphism and leukemia, but also between its enzyme activity and leukemia. We found no significant differences in allele and genotype frequencies of CAT polymorphism between healthy controls and patients with leukemia. On the other hand, TT genotype of C262T polymorphism led to decreased CAT enzyme activity in leukemia patients, although this did not reach statistical significance. The reason could be the small sample size of patients with TT genotype. However, leukemia can be considered as an age-related disease, because it is clearly shown that the incidence of leukemia patients increases at older ages. Further studies are needed to assess the relationship between the CAT C262T polymorphism and its enzyme activity in leukemia with larger sample size.

\section{Acknowledgments}

This research was financially supported by grants from the Research Fund of Mersin University BAP-SBE TB(NEE)2009-8 DR.

\section{Conflict of interest}

The authors declare no conflict of interest.

\section{References}

1. Turrens JF. Mitochondrial formation of reactive oxygen species. J Physiol 2003; 552: 335-44. 
2. Landry WD, Cotter TG. ROS signalling, NADPH oxidases and cancer. Biochem Soc Trans 2014; 42: 934-8.

3. Kobashigawa S, Kashino G, Suzuki K, Yamashita S, Mori H. lonizing radiation-induced cell death is partly caused by increase of mitochondrial reactive oxygen species in normal human fibroblast cells. Radiat Res 2015; 183 : 455-64.

4. Ghaffari S. Oxidative stress in the regulation of normal and neoplastic hematopoiesis. Antioxid Redox Signal 2008; 10: 1923-40.

5. Yorimitsu T, Klionsky DJ. Eating the endoplasmic reticulum: quality control by autophagy. Trends Cell Biol 2007; 17: 279-85

6. Briegera K, Schiavonea S, Miller FJ Jr, Krausea KH. Reactive oxygen species: from health to disease. Swiss Med Wkly 2012; 142: w13659.

7. Yang HY, Lee TH. Antioxidant enzymes as redox-based biomarkers: a brief review. BMB Rep 2015; 48: 200-8.

8. Sicinska P, Bukowska B, Pajak A, et al. Decreased activity of butyrylcholinesterase in blood plasma of patients with chronic obstructive pulmonary disease. Arch Med Sci 2017; 13: 645-51.

9. Eras-Erdogan N, Akbas E, Senli H, Kul S, Colak T. Relationship between polymorphism in the manganese superoxide dismutase gene and breast cancer. Mutat Res 2009; 680: 7-11.

10. Dutkiewicz G, Domanski L, Pawlik A, et al. Polymorphisms of superoxide dismutase, glutathione peroxidase and catalase genes in patients with post-transplant diabetes mellitus. Arch Med Res 2010; 41: 350-5.

11. Rindler PM, Cacciola A, Kinter M, Szweda L. Catalase-dependent $\mathrm{H}_{2} \mathrm{O}_{2}$ consumption by cardiac mitochondria and redox-mediated loss in insulin signaling. Am J Physio Heart Circ Physiol 2016; 311: H1091-6.

12. Forsberg L, de Faire U, Morgenstern R. Oxidative stress, human genetic variation, and disease. Arch Biochem Biophys 2001; 389: 84-93.

13. Matés JM, Perez-Gomez C, Núñez de Castro I. Antioxidant enzymes and human diseases. Clin Biochem 1999; 32: 595-603.

14. Quan F, Korneluk RG, Tropak MB, Gravel RA. Isolation and characterization of the human catalase gene. Nucleic Acids Res 1986; 14: 5321-35

15. Kodydková J, Vávrová L, Kocík M, Žák A. Human catalase, its polymorphisms, regulation and changes of its activity in different diseases. Folia Biol (Praha) 2014; 60: 153-67.

16. Góth L, Rass P, Páy A. Catalase enzyme mutations and their association with diseases. Mol Diagn 2004; 8: 141-9.

17. Liu K, Liu X, Wang M, et al. Two common functional catalase gene polymorphisms (rs1001179 and rs794316) and cancer susceptibility: evidence from 14,942 cancer cases and 43,285 controls. Oncotarget 2016; 7: 62954-65.

18. Ahn J, Nowell S, McCann SE, et al. Associations between catalase phenotype and genotype: modification by epidemiologic factors. Cancer Epidemiol Biomarkers Prev 2006; 15: 1217-22.

19. Sousa VC, Carmo RF, Vasconcelos LR, et al. Association of catalase and glutathione peroxidase 1 polymorphisms with chronic hepatitis C outcome. Ann Hum Genet 2016; 80: 145-53.

20. Hu J, Feng F, Zhu S, et al. Catalase C-262T polymorphism and risk of prostate cancer: evidence from meta-analysis. Gene 2015; 558: 265-70.

21. Castaldo SA, da Silva AP, Matos A, et al. The role of CYBA (p22phox) and catalase genetic polymorphisms and their possible epistatic interaction in cervical cancer. Tumour Biol 2015; 36: 909-14.
22. Zarafshan SS, Salehi Z, Salahi E, Sabet EE, Shabanipour S, Zahiri Z. Polymorphism of catalase gene (CAT C-262T) in women with endometriosis. J Obstet Gynaecol 2015; 35: 269-71.

23. Khodayari S, Salehi Z, Fakhrieh Asl S, Aminian K, Mirzaei Gisomi N, Torabi Dalivandan S. Catalase gene C-262T polymorphism: importance in ulcerative colitis. J Gastroenterol Hepatol 2013; 28: 819-22.

24. Bănescu C, Trifa AP, Voidăzan S, et al. CAT, GPX1, MnSOD, GSTM1, GSTT1, and GSTP1 genetic polymorphisms in chronic myeloid leukemia: a case-control study. Oxid Med Cell Longev 2014; 2014: 875861.

25. Bănescu C, lancu M, Trifa AP, et al. From six gene polymorphisms of the antioxidant system, only GPX Pro198Leu and GSTP1 lle105Val modulate the risk of acute myeloid leukemia. Oxid Med Cell Longev 2016; 2016: 2536705.

26. Eras N, Tombak A, Tiftik N, et al. Association between PON1 L55M polymorphism and PON1 enzyme activity in patients with leukemia. UHOD 2017; 27: 21-8.

27. Forsberg L, Lyrenäs L, de Faire U, Morgenstern R. A common functional C-T substitution polymorphism in the promoter region of the human catalase gene influences transcription factor binding, reporter gene transcription and is correlated to blood catalase levels. Free Radic Biol Med 2001; 30: 500-5.

28. Aebi H. Catalase in vitro. Methods Enzymol 1984; 105: 121-6.

29. Beerman I, Seita J, Inlay MA, Weissman IL, Rossi DJ. Quiescent hematopoietic stem cells accumulate DNA damage during aging that is repaired upon entry into cell cycle. Cell Stem Cell 2014; 15: 37-50.

30. Abdelsalam L, Elshobaky MA, El-araby RE, et al. Expression of beclin-1 and apoptosis-related genes in childhood acute lymphoblastic leukemia. Arch Med Sci Civil Dis 2017; 2: e168-73.

31. Petersen M, Hofius D, Andersen SU. Signaling unmasked: autophagy and catalase promote programmed cell death. Autophagy 2014; 10: 520-1.

32. Suzen HS, Gucyener E, Sakalli O, et al. CAT C-262T and GPX1 Pro198Leu polymorphisms in a Turkish population. Mol Biol Rep 2010; 37: 87-92.

33. Tefik T, Kucukgergin C, Sanli O, Oktar T, Seckin S, Ozsoy C. Manganese superoxide dismutase lle58Thr, catalase C-262T and myeloperoxidase G-463A gene polymorphisms in patients with prostate cancer: relation to advanced and metastatic disease. BJU Int 2013; 112: E406-14.

34. Zarbock R, Hendig D, Szliska C, Kleesiek K, Götting C. Pseudoxanthoma elasticum: genetic variations in antioxidant genes are risk factors for early disease onset. Clin Chem 2007; 53: 1734-40.

35. Mak JC, Ho SP, Yu WC, et al. Polymorphisms and functional activity in superoxide dismutase and catalase genes in smokers with COPD. Eur Respir I 2007; 30: 684-90.

36. Shen Y, Li D, Tian P, et al. The catalase C-262T gene polymorphism and cancer risk: a systematic review and meta-analysis. Medicine (Baltimore) 2015; 94: e679.

37. Quick SK, Shields PG, Nie J, et al. Effect modification effect modification by catalase genotype suggests a role for oxidative stress inthe association of hormone replacement therapy with postmenopausal breast cancer risk. Cancer Epidemiol Biomarkers Prev 2008; 17: 1082-7.

38. Chistiakov DA, Zotova EV, Savost'anov KV, et al. The $262 \mathrm{~T}>\mathrm{C}$ promoter polymorphism of the catalase gene is associated with diabetic neuropathy in type 1 diabetic Russian patients. Diabetes Metab 2006; 32: 63-8.

39. Ho JC, Mak JC, Ho SP, et al. Manganese superoxide dismutase and catalase genetic polymorphisms, activity levels, and lung cancer risk in chinese in Hong Kong. J Thorac Oncol 2006; 1: 648-53. 